\title{
So what? The power of action centred research to change perceptions
}

\section{The Library and Information Research Group Annual Lecture held at Bloomsbury Theatre, London on 27 March 2002}

\section{Grace Kempster}

I am so delighted to be with you this afternoon to offer you reflections and I hope provocation!

In preparing for this talk, I reflected on some very happy times at Aberystwyth doing my Masters by distance learning. I vividly remember sitting in the library and reading the inspiration of an article from the American Library Association about children's use of libraries called "Are smiles measurable?" I always feel a satisfying clunk when seeing the experience of others so clearly articulated and to find a sense of camaraderie that while our answers may vary or be differently faceted; our questions are the same. I also enjoy the quirky parallels I have found where the processes in libraries can be aligned with those in the arts, in creative leisure, and in learning.

I also relish the integrity of research well done - where the facts are well argued and cannot be gainsaid. Where the key messages can be picked up and spun into the gold of winning argument and investment. Yesterday, in Manchester our team had Bob Usherwood with us. I was so excited when I first heard of his work on the social impact of libraries because I had long been wrestling with the arguments - if the library suddenly disappeared overnight what would be the result? He was able to use the Sheffield strike as a real life opportunity to show what does happen and I think for the first time show and evidence the powerful nature of 'libraryness' in ordinary lives. Something so deeply woven into the fabric of daily living that it needed such an opportunity and also a rigour to distil it - to uncover and reveal its importance.

However I have been more manager than researcher to date and therefore my approach will be as user and I hope helpful to you as you reflect on current challenges and opportunities.

A sticking point, which I had in preparing for today, was the word itself: "research". The Oxford English Dictionary defines it as "careful search or enquiry; endeavour to discover new facts by scientific study of a subject; course of critical investigation".

I have no problem with the definition at all but the cultural surround of the word itself leaves me cold. How many of us have often read in the media of research that has cost much and simply affirmed the bleeding obvious? How many of us have experienced the reading of research proposals or reports and been as clueless as to what it was all about at the end as we were at the start? Who amongst you have reflected to yourself that the research you are engaged in is nice and interesting but will not add to the sum of things - if anything maybe complicate and obfuscate them more? 
I think there are games being played which to be frank we do not have time for. I see students re-inventing the wheel and making up areas for investigation (usually the same ones again and again) when the real questions are hungry to be answered. I see research effort as seeking to meet the language and requirements of an academic environment which only seeks to perpetuate its own codes and behaviours - I shall say something about the perceived threat to professional skills later. And while this small and introverted wheel whirrs we have seismic changes that need the touchstone and the assaying of good and wholesome research calibre attention.

"Careful search to discover new facts" - now that's the buzz for me - to reveal, to incontrovertibly expose something new and of value. That is the touchstone of action centred and meaningful research activity that I want to talk about today.

Everything is so very uncertain, that's exactly what makes me feel reassured. In the maelstrom of change and pace acceleration that surrounds us today in the library and information world, everyone is seeking touchstones for a future that is increasingly unpredictable. There is a sense that nothing that has gone before can be a predictor of what is to come. We occupy new and fused territories with increasingly mature customer or client expectations. I was once happy to wait in a queue at a bank to get some money out - now if the ATM experience takes more than a minute I am frustrated. This amnesia of the recent past is the price of progress and is equally true in our environment. New users, new uses of services are exploding and that means a quite different approach to the reflective nature of research.

My challenge to you is that research must transform itself to align with the changes and not follow them. To have any power or influence in today's world, it must work alongside developments, not as a fixed-point intervention.

Let me give you an example. Three years ago, the Arts Council funded a programme called Branching Out to transform 33 librarians into reading animateurs across the UK. Opening the Book who were directors of the programme had enormous foresight to include in the consortium the University of Central England in Birmingham and used Briony Train as the researcher. She tracked initial views and skills of the participants through interview and diary to set the starting point and then followed the development of skills in these people. Because of that sustained involvement and the evidence of difference made, the same programme is about to start in Wales and Scotland with every local authority participating. It is this kind of working alongside people that I think is so powerful. It is also the translation skills of Briony. She had, I think, two versions of the research outputs: the in-depth and highly credible research speak and also - critically - the 'lite' version for busy managers asking "So what?"

Now I am for good and ill an impatient person. I want the vision of services now not tomorrow and I am working in a political environment where moving the goalposts is a norm. I try to keep half a step ahead of the expectations of others using the true mantra of marketing - to identify, anticipate and satisfy need. Therefore in one way I miss out - on the reflective phase of looking around to see who else is doing what; on the other hand I win by seizing the moment and just doing it.

In the British Council, we are at the early stages of rolling out over 50 Knowledge and Learning Centres (KLC) world-wide. We launched the first pilot in Delhi in January 
in the presence of the Prime Minister and the second last week in Belgrade accompanied by a four-way global dialogue with young people in Kiev, Oxford, Paris and Belgrade on the death of national identity in Europe. The programme and the network will cost many millions and the Government will rightly want to know "So what?" Has this connecting and fusing of library and learning experiences worked? Are the stories we have told about Dragan in Belgrade and Kofi in Accra come true? Is it accelerating the Council's core purpose of effective cultural relations world-wide - and by how much? The challenge is that they want the answers to these questions before the evidence. They want now a predictor of impact and effect and return on investment. I am quite content that through longitudinal tracking we can evidence this over time - but where is research in all this? That magic touchstone of credibility and quality assurance? I have to keep reminding colleagues that some things we can predict - like the use of video conferencing to assuage the tyranny of distance - and other things will simply be a surprise. Other things we can learn about through transferability from other activity. For example the knowledge that the take up of elearning is going to be culturally and contextually defined. The possibility may be with us - but do the people want it yet?

We aim to do an independent assessment of progress in March 2003 when we will have about 12 centres up and running. The conundrum for us is to extract the KLC effect in a situation where there are many other factors - the team strength of the office; the leadership skills of the country director; the other financial drivers and of course the willingness to change. Boy, is it complex and challenging - and wholly engaging!

To distil the impact will take finesse and facts. I need the rigour of research to change minds and perceptions - to alter those closed and fixed in their views.

\section{Research without walls}

But am I aware of current research that could be just what I need to refer to? I think not. As a leader of services for over 10 years, have I sought refreshment or an update on LIS research in the UK today? Well, I have always been a LIRG member - but the focus is on the nature of the research not it's context - the "so what?" factor. And noone is offering me a leader's guide to the LIS research landscape now - nor I confess have I articulated this. I do not wish to mount my hobbyhorse of Continuing Professional Development (CPD) but there lies the issues and I am sorry that CILIP does not see this as a key and top priority on 1 April.

I also think that research has seemed to thrive more in the academic environment because there is a common language and understanding - a mores on the value of going deep. This is not the case in public service and in workplace environments. And yet there is a kind of re-invention of research in the fashion for knowledge management or governance. The memory loss of staff turnover and short term employment is being taken seriously in the competitive knowledge economy. We see research as one facet of knowledge in an organisation which includes the tacit peopleto-people know-how through to the information for purpose delivered pro-actively through to the evidence based activity that can be replicated - and fast for business advantage. But it is not joined up. It carries a stigma of taking too long, costing too much, being too difficult and missing the mark of direct relevance. 
So can there be a new alignment of research and delivery? In the context of the rigours of Best value in the public sector I would certainly say so. Quite frankly, we are not being very professional about our knowledge - we cannot leave good action centred research to the vagaries of happenchance and whether service leaders can bother to update their skills or translate the language of the research world. It needs effort and change on all sides because the results evidencing the impact matter enormously to us all.

In Essex, we worked with Francois Matarasso of Comedia to establish the Social Impact of the Arts study. It was a brilliant experience because the annual conference, which it began with, did something both difficult and important - it got ownership and agreement for the core questions we needed to ask over time. Surveying over 1000 arts organisations with these issues and covering complex direct and indirect effects and impacts we were able to establish trends - and that gave us predictors. It meant that last March we achieved $£ 250,000$ growth in the arts grants for organisations. The simple fact we could distil and evidence was that for every $£ 1$ spent on the arts in Essex $£ 17$ of arts activity was generated. Such a multiplier mattered - and it changed perceptions of those sceptical about the financial power of creative leisure.

\section{Crossing boundaries}

We need to cross the boundaries of impact and look together at social, financial, environmental audits. The sum of the parts gives us greater knowledge and understanding of their complex intertwining. Hence our use of the balanced scorecard for our information services worldwide and the same rich picture for evaluating our Knowledge and Learning Centres.

A business knows that its brand or reputation sells more than its marketing. In every context, the brand of library and information services is good. Trustworthiness, the underlying codes of doing things right is shared - but is this enough? I suggest that we need to be bolder and more daring. I see the Public Lending Right figures making the news each year because of the interest in what it tells us about our reading habits today - I do not see the same coverage for the LIST [Library and Information Statistics Tables].

Peter Honey once said, "It is better to be roughly right than precisely wrong". Actually this is not a challenge to research and its essential values of thoroughness and rigour - rather to the uses and timeliness of research. How the results are finessed; how the processes are integrated with activity - alongside, not after and looking forward, not back. These are my key messages to you today.

As we hold the ambiguity of research endeavour caught between two worlds I would argue that this could be and should be a creative tension. We all increasingly span differences and if all the research and work is not to be nugatory we need to make research work. If research is not relevant, then it will not survive. We waste much time talking about each other rather than with each other. I have often thought that job swaps and attachments would be a good thing - to understand just how differently the worlds of each spin. 


\section{The democratisation of knowledge}

It is a truism to say that everyone claims to have knowledge navigation skills today and in the same way, a bit of market research will do the trick - who needs researchers anyway? My issue is that there is a place for quick and dirty research. Our watchword in Information Services in the British Council is Launch and Learn we see the process as iterative and instructive and see ourselves as striving to be a learning organisation. However, just experience can be hard - in this you get the test first and the lessons afterward. Yes, we have the market research. Through Other Eyes is a great MORI survey of fascinating perceptions of how the UK is viewed around the world. Yet if we do not have before us all the relevant facts, all the relevant learning from other spheres and activities then the results will not be as good as they could be. For instance we will make informed choices that could be better; we will make judgements that could be of a higher calibre. Like everyone else we want the journey to be one of continuous improvement.

In the British Council we are grateful to Peter Brophy for his Ladder of Perceptions which demonstrates I think the complexity of any organisation. We are trying to achieve something very hard that is open to luck and happenchance as well as our own influence. Frankly we have to measure, to indicate on this because this is the essence of why we exist - to win recognition for the UK and create enduring and sustainable partnerships worldwide.

\section{Insert Ladder of Perceptions Figure}

The week before last we brought together young people from ten Muslim countries for a youth forum signalling the start of Connecting Futures. Over the next 10-15 years we will track changing perceptions and views of these young people. Our aim is simple to keep the talking going. If we have learned anything in the last few months, it is that talking and keeping talking matters; respect and understanding across cultural divides matters and that we inhabit a highly interconnected world. Sometimes keeping people in neutral rather than turning hostile will be enough.

\section{Conclusion}

Research then is too important to be left to researchers, too important for everyone not to have some research skills - how are you sharing these? Are there toolkits for research in a hurry? Where is the democratisation of this knowledge base when the needs are so great? Are you being precious about it? Is every new information professional being equipped with basics in skills to evidence impact? Are there updates for old lags like me who are just not keeping up? Are you seeing your role as a QA for other research? Have we the imagination to break out of the old tramlines of accusation to find new bargaining chips? Can I have a researcher in residence maybe online? Can the next public library staff skilling module as part of the People's Network be in basic evidencing? Is money the only currency that matters - would swapped experiences count? Can we spin our worlds closer, align our priorities on the key issues of impact and evidence?

My closing remarks are to the young researchers present and it is simply this. Never stop asking the question "So what?" and ensure your voice is heard amidst the cacophony of others. Believing in what you do matters so much. If others are not 
hearing your messages - well it is your problem not theirs. Hone your negotiating skills - and align your cause.

The British Council's by-line when it was first formed in the turbulent 1930's (definitely a calm before the gathering stormclouds over Europe) was this: "Truth will triumph". I think it could be our mantra today - for library and information professionals making a difference in lives globally. We are all about animating knowledge - let's just do it.

\section{Word count 2,910}

